\title{
Mechanical and morphological study of rice husk reinforced LDPE composites with organic filler
}

\begin{abstract}
The mechanical properties of rice husk composites were studied for various range of rice husk $(0 \%, 10 \%, 15 \%$, and $20 \%)$ filled low density polyethylene. Natural fibers extracted from plants gained attention owing to their advantage over synthetic polymers. Nowadays composites prepared with natural fibers are among the most keenly required materials. In the present study raw rice husk is treated in order to enhance the properties. The purpose of using annealing method is to increase the rate of reaction. Goal of this study is to observe the effect of chemical treatment to enhance the properties of rice husk that may be used as reinforcement in polymers to make ecofriendly, lightweight, biodegradable polymer composites. The properties of (LDPE/rice husk (RH)) composites are analyzed as a function of the rice husk amount. Modification in morphology of rice husk with treatment is observed through SEM technique. All prepared composites showed improved fibers dispersion in the low density polyethylene matrix. All composites displayed lower elongation of break compared to pure LDPE.
\end{abstract}

Keywords: rice husk, LDPE, tensile strength, polymer composites
Volume I Issue I - 2017

Sharma J, Bapat MN

Regional Institute of Education, RIE Bhopal, India

Correspondence: J Sharma, Regional Institute of Education, RIE Bhopal, India, Email janu.sharma87@gmail.com

Received: April 26, 2017 | Published: July 13, 2017

\section{Introduction}

Low density Polyethylene is a famous commercial polymers used in a many industrial applications. It is also used as insulating material. Along with this it possess excellent mechanical properties (high tensile strength) make it as an active material replacing other materials. Characteristics of polymers can be controlled and altered by adding different additives and fillers. ${ }^{1}$ Various parameters, concerning this response, are measured and investigated, such as, young's modulus, elongation, tensile strength stress at a yield and break, impact and hardness. Fiber reinforced polymer matrix composites (PMCs) are widely used in various applications, i.e., aerospace, defense, automotives, marine and sporting goods due to their high specific stiffness and strength. These materials provide high durability, design flexibility and lightweight which makes them attractive in various applications. ${ }^{2}$ Elementary advantage of utilizing natural fibers is that they are biodegradable and renewable, exhibit low cost, low density, high toughness and good thermal resistance. Moreover polymers reinforced with natural fibers (jute, rice husk, hemp, sisal, woodfiber, etc.) can combine satisfactory mechanical properties with a low specific mass. ${ }^{3}$

Superior specific strength and stiffness, corrosion resistance, high specific modulus makes the natural fibres most striking and suitable for different engineering application. ${ }^{4}$ There is a huge amount of agricultural waste, including rice husk (RH), coconut coir, jute fibre which can be effectively utilized for a sustainable advance. About 20 percent of the whole rice in the rice milling industry ended up with the production of RH as its by-product. ${ }^{5}$ Agricultural waste may be employed as energy supply on continual searches for renewable resources of energy. Rice husk can be taken into account as a considerable energy resource potential, becoming a significant part of the nation's matrix of energy. ${ }^{6}$

Mechanical properties of natural fibres are dependent on the cellulose content in the fibre. Joseph et al. ${ }^{7}$ reported the cellulose content i.e. of $85-88 \%$ in sisal fibres (extracted from the leaves). ${ }^{7}$ Singleton et al. ${ }^{8}$ reported that the henequen which are extracted from the bast, have $60 \%$ cellulose content. Latest developments showed that it is possible to improve the mechanical properties of cellulose fibre-reinforced composites by chemical modification that can provide good adhesion with the fibres. Reinforcement mechanism is dependent on the stress transfer between the matrix material and the embedded fibre. The fibre-matrix interfacial shear strength is one of the most important parameters in controlling the toughness and the strength of a composite material. ${ }^{9-12}$ A number of studies reported on the effect of poor or good interfacial adhesion on the mechanical and viscoelastic properties of the polyolefin/natural fibre composite materials. Polymer modification is a quick, effective method to provide good interfacial adhesion, in distinction to fiber modification, which mostly involves solvent based processes. The aim of this study is to find out the effect of adding rice husk on mechanical properties of polyethylene.

\section{Material and methods}

The Rice Husk used in the present study was collected from Betul M.P. (India) in the form of agriculture residues. Low density polyethylene (LDPE), trade name Indothene, grade 16MA 400 was obtained Indian Petrochemicals Corporation Limited (IPCL), Vadodara (India) with density $919 \mathrm{~kg} / \mathrm{m}^{3}$. Cenospheres of flyash used in this investigation were obtained from Cenosphere India Pvt. Ltd. Kolkata of size $150 \mu \mathrm{m}$ with density $600 \mathrm{~kg} / \mathrm{m}^{3} .^{13}$

\section{Composite preparation}

Different composites were prepared by varying the concentration of rice husk and cenosphere. Method adopted to prepare these composites is discussed in our previous communication. ${ }^{13}$ Samples thus prepared are listed in (Table 1) with our coined mnemonics.

* LDPE- low density polyethylene, MA -Maleic Anhydride, Treated, $\mathrm{RH}$ - rice husk 
Table I Lists the samples with their coined mnemonics

\begin{tabular}{lll}
\hline S.N & Sample* & Mnemonics \\
\hline I & Pure LDPE & LD \\
2 & LDPE/Rice Husk $(70 / 30)$ & LDRH30 \\
3 & LDPE/ Rice Husk $(80 / 20)$ & LDRH20 \\
4 & LDPE/ Rice Husk $(90 / 10)$ & LDRHI0 \\
5 & LDPE/ MATr. Rice Husk $(70 / 30)$ & LDTRH30 \\
6 & LDPE/MATr. Rice Husk $(80 / 20)$ & LDTRH20 \\
7 & LDPE/ MATr. Rice Husk $(90 / 10)$ & LDTRHI0 \\
\hline
\end{tabular}

\section{measurements}

Density of the samples was determined by using a high precision Citizen machine, Model CX 265 following ASTM D 792. An average of four samples is reported here. The sample was weighed in air $(W)$ and in the distilled water (Ww) as well. The density $\rho$ of the sample was estimated using following formula

$$
\rho=W \rho w a t e r /\left(W-W_{w}\right)
$$

Where, water is the density of distilled water.

\section{Tensile properties}

Tensile testing was performed on Universal testing machine, Model-UT 10 made by Scientific Testing India as per ASTM D 638. Tensile strength, elongation and tensile modulus of the samples were determined at $10 \mathrm{~mm} / \mathrm{min}$ cross head speed.

\section{Hardness}

Hardness of the samples was measured following ASTM D 2240, by using Hiroshima Hardness Tester (Udometer Model RHT-1) at room temperature. The tester was kept in the vertical position and samples were placed on a horizontal surface. The pyramid shaped indentation pin of the Udometer was pressed on the specimen, and was kept in such a manner, so that the pressure foot remained parallel to the specimen. An average of six readings was reported.

\section{Impact testing}

Impact strength of the specimen was determined by using Impact Pendulum Tester CEAST, Italy. Samples were tested under IPod (unmatched) Impact Test conditions following ASTM D 4812

\section{SEM characterization}

A Scanning Electron Microscope (SEM); model JEOL JSM 5600 (Japan) was used to observe the microstructure of surfaces of particles and fibre filled composites. Composites were gold coated under vacuums as per requirement prior to surface observation. The surfaces for its morphological studies were first polished with gold. Many researchers, however, polish with silver or carbon. But their longevity is very less hence gold polish is preferred silver polish oxidizes or contaminated within a few hours after formation whereas carbon polishing loses its property on attracting dust or leaves the surface with small jerks also.

\section{Discussion}

It is clear from the Table 2 that there is a little difference between the densities of all the samples. Interestingly for LDPE composites with treated rice husk lower the incremental gradient as compared to untreated rice husk filled composites. This may also be due to (I) untreated rice husk filling up voids in the composite. Upon treatment the size of rice husk might not be that easily fill up the void. (II) The untreated cenosphere hardly fill voids in the composite upon treatment again the size of cenosphere mismatch might remain.

If the above preposition is accepted then according to point (I) density value must increase with untreated rice husk whose rate of increment may be reduced, with increase in filler concentration.

Mechanical properties of fibre reinforced composites are of great importance for structural applications. Tensile strength, modulus etc., generally increases with the natural fibre reinforcement. With the increase in fraction of reinforcing rice husk increases the strength and modulus of composites. The trend of increasing the strength and modulus continues until a critical packing density is achieved beyond which voids, non-wettability, etc. dominate the trend and strength goes down.

The data plotted in figures indicates that modulus variation is comparatively insignificant in low strain region for all composites as well as almost same. It is observed in for $80 / 20$ composition specific stress good as comparative to other compositions and also the treated composites also. Ultimate tensile strength increases with the content of rice husk content. Improvement in materials modulus may be attributed to compaction of rice husk content.

Table 2 Lists the mechanical properties of rice husk filled LDPE composites

\begin{tabular}{llllllll}
\hline S.No. & Sample & $\begin{array}{l}\text { Density } \\
\left(\mathbf{g} / \mathbf{c m}^{3}\right)\end{array}$ & $\begin{array}{l}\text { Elongation } \\
(\text { Elon. } \% / 100)\end{array}$ & $\begin{array}{l}\text { Stress at } \\
\text { break (MPa) }\end{array}$ & $\begin{array}{l}\text { Ultimate tensile } \\
\text { strength }(\mathbf{M P a})\end{array}$ & $\begin{array}{l}\text { Impact strength } \\
\left(\mathbf{k J} / \mathbf{m}^{2}\right)\end{array}$ & $\begin{array}{l}\text { Hardness } \\
(\text { Shore } \mathbf{D})\end{array}$ \\
\hline I & LD & 0.919 & & & & 100 & 43.83 \\
2 & LDRH30 & 0.995 & 6.43 & 5.73 & 8.28 & 74 & 42.16 \\
3 & LDRH20 & 0.982 & 5.48 & 8.4 & 8.69 & 34.54 & 39.16 \\
4 & LDRHI0 & 0.956 & 4.23 & 4.3 & 6.59 & 84.71 & 43.16 \\
5 & LDTRH30 & 0.981 & 8.01 & 5.61 & 7.11 & 56.85 & 41.16 \\
6 & LDTRH20 & 0.966 & 6.82 & 5.58 & 7.76 & 30.1 & 36.5 \\
\hline
\end{tabular}


This also makes composites more environments friendly. The mechanical properties such as tensile modulus and strength are influenced by the length of reinforcing material. Though these short rice husk particles did not contribute in tensile strength they still filled up the voids and gaps available in the inter fibre spacing and thus improved packing density, which manifested in improved modulus.

The morphological study of these composites gives a clear picture of the phenomenon that contributed successful reinforcement of rice husk in the composites. The study of impact fractographs indicates a dominating role of reinforcement. The morphological evidence of rice husk the reason for low impact strength of fiber composites as compared to high strength fibre composites.

\section{Tensile test parameters used:}

a. Load Range: $100 \mathrm{~N}$

b. Extension Range: $20 \mathrm{~mm}$

c. Gauge Length: $30 \mathrm{~mm}$

d. Test Speed: $1.0 \mathrm{~mm} / \mathrm{min}$

The effect of fiber loading on the tensile properties of LDPE rice husk composites is shown in Figures 1-3 above. It is found that the tensile strength of composites decreases with the increase in weight percentage of fiber. The decrease in tensile strength of LDPE rice husk composite may be due to poor bonding between rice husk and LDPE. The inclusion of fiber into the matrix leads to the poor distribution of fibers because of strong inter fiber hydrogen bonding which keeps fibers together, as a result the resin does not wet the gathered fibers properly. Observations show that the tensile modulus of LDPE rice husk composite increases significantly with the increase in fiber content. Increase in tensile modulus indicates that the stiffness of LDPE rice husk composite increases with the increase in fiber loading.

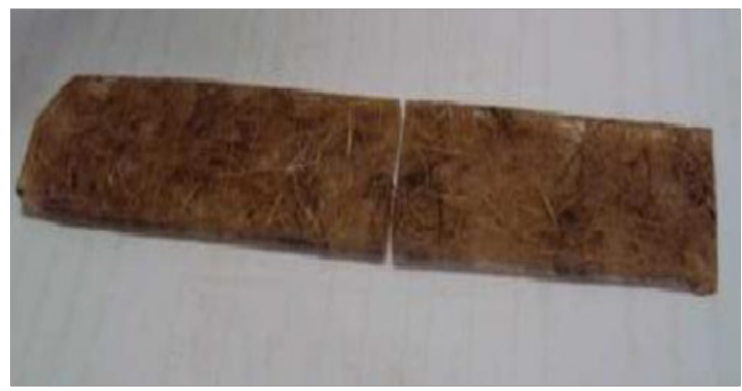

Figure I Photograph of composite prepared.

The SEM micrographs of the composites are shown in Figure (3A, 3B \& 3C) respectively. Irrespective of the rice husk addition, all micrographs show more or less fragile-type bonding. This implies that these matrices exhibit plastic behavior. The micrographs further reveal that the rice husk particles are uniformly distributed throughout the LDPE matrix. With the increase in filler concentration, the aggregation of rice husk with LDPE particles increases, which increase porosity of composite. Composite appears homogenous, thus indicating that blending was effective. Plates a and c reveal poor adhesion of the filler to matrix is evident from the voids between the matrix and rice husk particles. These voids act as stress concentration points and detrimental to mechanical properties.

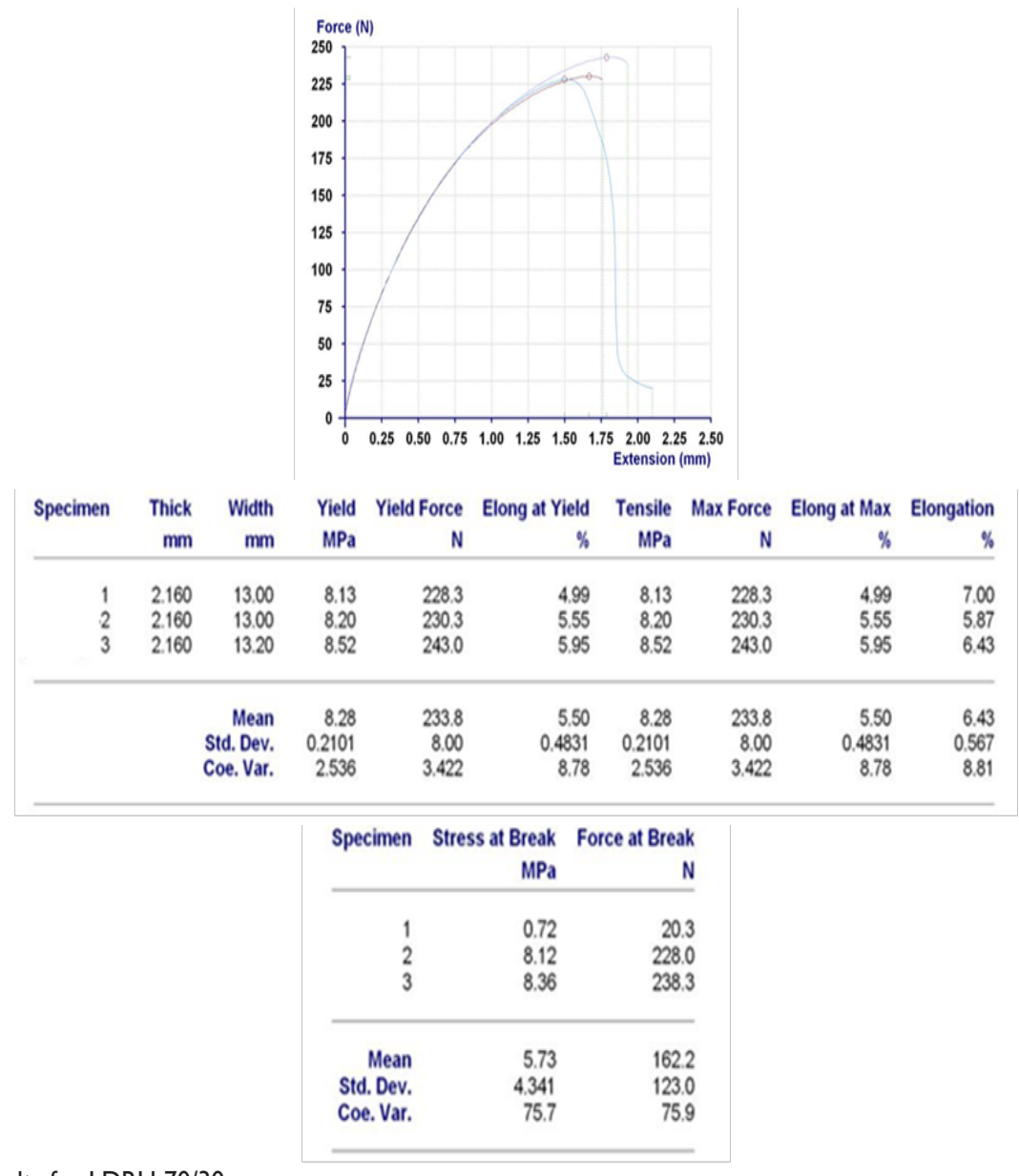

Figure 2 Shows the tensile results for LDRH 70/30. 


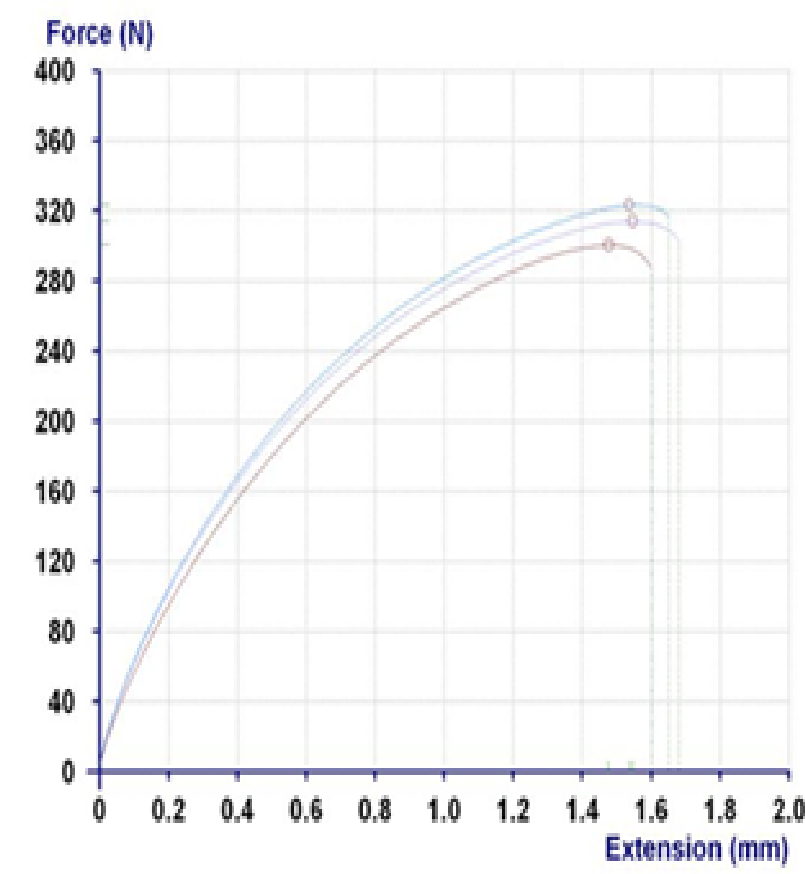

\begin{tabular}{|c|c|c|c|c|c|c|c|c|c|}
\hline Specimen & $\begin{array}{r}\text { Thick } \\
\text { mm }\end{array}$ & $\begin{array}{r}\text { Width } \\
\text { mm }\end{array}$ & $\begin{array}{l}\text { Yield } \\
\text { MPa }\end{array}$ & $\begin{array}{r}\text { Yield Force } \\
\text { N }\end{array}$ & $\begin{array}{r}\text { Elong at Yield } \\
\%\end{array}$ & $\begin{array}{r}\text { Tensile } \\
\text { MPa }\end{array}$ & $\begin{array}{r}\text { Max Force } \\
\mathrm{N}\end{array}$ & $\begin{array}{r}\text { Elong at Max } \\
\%\end{array}$ & $\begin{array}{r}\text { Elongation } \\
\%\end{array}$ \\
\hline $\begin{array}{l}1 \\
2 \\
3\end{array}$ & $\begin{array}{l}3.000 \\
3.000 \\
3.000\end{array}$ & $\begin{array}{l}12.00 \\
12.00 \\
12.00\end{array}$ & $\begin{array}{l}8.99 \\
8.36 \\
8.73\end{array}$ & $\begin{array}{l}323.6 \\
300.8 \\
314.4\end{array}$ & $\begin{array}{l}5.12 \\
4.92 \\
5.15\end{array}$ & $\begin{array}{l}8.99 \\
8.36 \\
8.73\end{array}$ & $\begin{array}{l}323.6 \\
300.8 \\
314.4\end{array}$ & $\begin{array}{l}5.12 \\
4.92 \\
5.15\end{array}$ & $\begin{array}{l}5.50 \\
5.33 \\
5.60\end{array}$ \\
\hline & & $\begin{array}{l}\text { Mean } \\
\text { Std. Dev. } \\
\text { Coe. Var. }\end{array}$ & $\begin{array}{r}8.69 \\
0.3186 \\
3.665\end{array}$ & $\begin{array}{l}312.9 \\
11.47 \\
3.666\end{array}$ & $\begin{array}{r}5.06 \\
0.1262 \\
2.492\end{array}$ & $\begin{array}{r}8.69 \\
0.3186 \\
3.665\end{array}$ & $\begin{array}{l}312.9 \\
11.47 \\
3.666\end{array}$ & $\begin{array}{r}5.06 \\
0.1262 \\
2.492\end{array}$ & $\begin{array}{r}5.48 \\
0.1347 \\
2.459\end{array}$ \\
\hline
\end{tabular}

\begin{tabular}{rrr} 
Specimen & $\begin{array}{r}\text { Stress at Break } \\
\text { MPa }\end{array}$ & $\begin{array}{r}\text { Force at Break } \\
\text { N }\end{array}$ \\
\hline 1 & 8.81 & 317.2 \\
2 & 7.98 & 287.2 \\
3 & 8.42 & 303.2 \\
& & \\
\hline & & \\
Mean & 8.40 & 302.5 \\
Std. Dev. & 0.4170 & 15.01 \\
Coe. Var. & 4.962 & 4.962
\end{tabular}

Figure 2A Shows the tensile results for LDRH 80/20. 


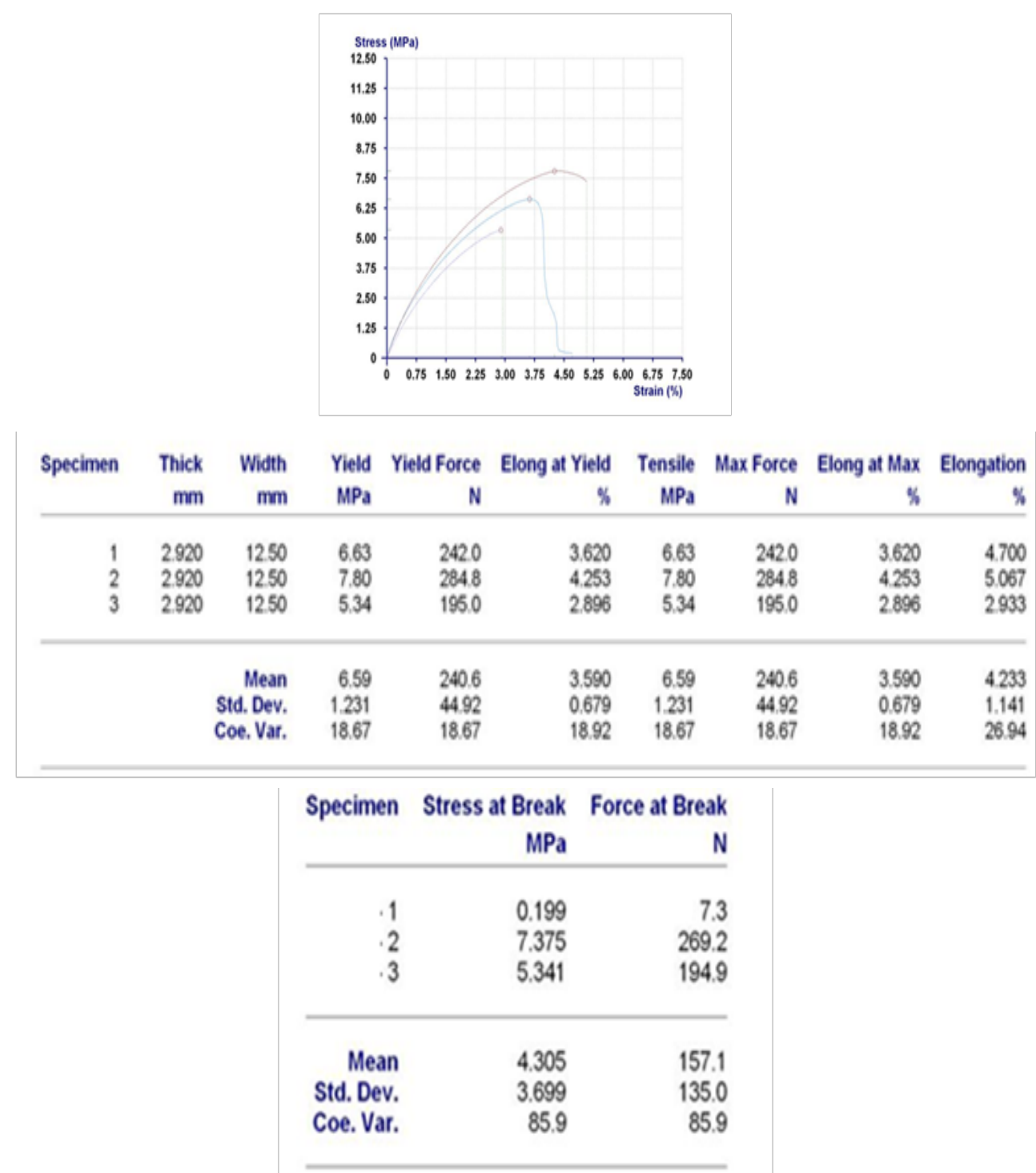

Figure 2B Shows the tensile results for LDRH 90/I0.

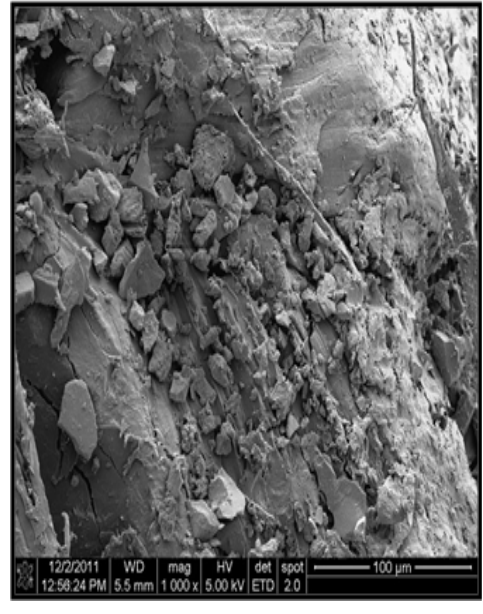

A

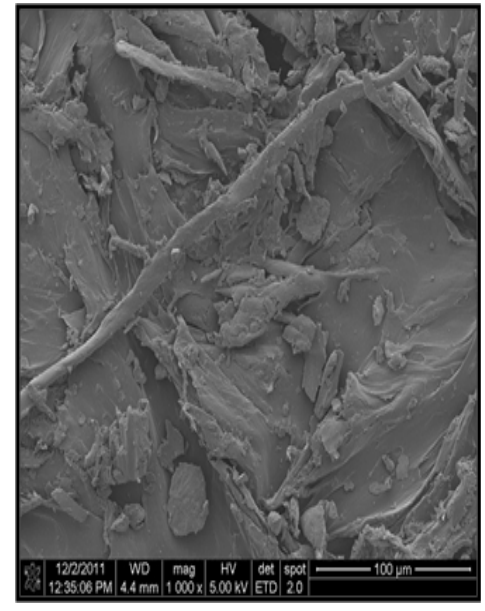

B

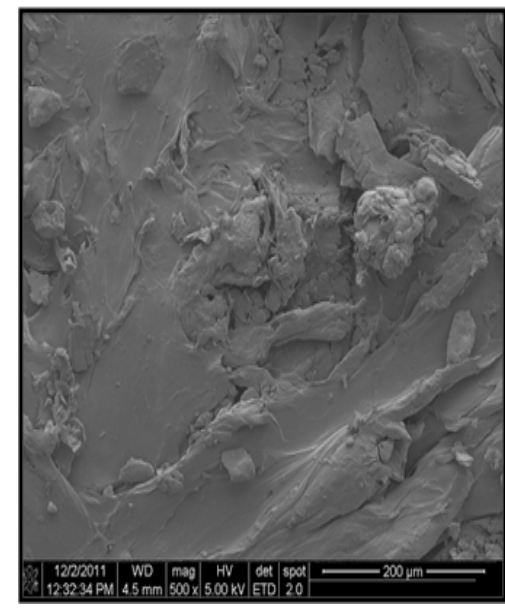

C

Figure 3 Shows the SEM micrographs of the composites. 


\section{Conclusion}

In this work rice husk has been used with LDPE in order to analyze its modified properties. This study showed an increase in strength in case with the rice husk addition in the composite is studied. This may be due to the increased fibre matrix adhesion which is investigated by SEM analysis. This confirms the surface modified characteristics of the rice husk which. The natural filler like hemp can be added in form of fibers where their effect on mechanical properties depends on their lengths and the concentration. The rice husk used as filler in this study improves the mechanical properties (stress-strain) and the best results with $20 \%$ content, the changing of added rice husk ratio certainly made a big changes to those mechanical properties like stress-strain, toughness and elongation due to the type of interaction between the polymers chains, fillers fibers and the filler polymer interaction.

\section{Acknowledgements}

None.

\section{Conflict of interest}

The author declares no conflict of interest.

\section{References}

1. Wael AS Abdul Ghafor, kalaf MN. Iraqi. J Polymers U. 2003;7(1):1116.

2. Einas A Al-Nasir. Study of the Tensile strength properties of Low density polyethylene composites with Cannabis (Hemp fibers). Journal of Basrah Researches. 2013;39(3):15-22.

3. Nabi Saheb D, Jog JP. Natural fiber polymer composites: a review. $A d v$ Polym Technol. 1999;18(4):351-363.
4. Munikenche Gowda, TA Naidu, R Chhaya. Composites Part A: Applied Science and Manufacturing. Composites Part A: Applied Science and Manufacturing. 1999;30(3):277-284.

5. Chan HY, Riffat SB, Zhu J. Review of passive solar heating and cooling technologies. Renewable and Sustainable Energy Reviews. 2010;14(2):781-789.

6. CEF Roger R Riehl, Luciano S De Souza, Dib Karam. Recent Advances in Energy. Environment and Development. 2013.

7. Yang S, Taha-Tijerina J, Serrato-Diaz V, et al. Dynamic Mechanical and Thermal Analysis of Aligned Vapor Grown Carbon Nanofiber Reinforced Polyethylene. Composites Part B: Engineering Composites. 2007;38:228-235.

8. Joseph PV, Joseph K, Thomas S, et al. Composites Part A. 2003;34:253266.

9. Dikobe DG, Luyt AS. Effect of poly(ethylene-co-glycidil methacrylate) compatibilizer content on the morphology and physical properties of ethylene vinyl acetate-wood fiber composites. Journal of Applied Polymer Science. 2007;104(55):3206- 3213.

10. Li Y, Hu C, Yu Y. Interfacial studies of sisal fiber reinforced high density polyethylene composites. Composites Part A. 2008;39:570-578.

11. Harper D, Wolcott M. Interaction between coupling agent and lubricants in woodpolypropylene composites. Composites Part A. 2014;35:385394.

12. Mahfuz A, Adnan A, Rangari VK, et al. Carbon nanoparticles/whiskers reinforced composites and their tensile response. Composites Part A. 2004;35:519-527.

13. Navin Chand, Sharma J, Bapat MN. Results in Physics. 2012;2:26-33. 